headache. A higher body mass index in children with nonspecific headache predisposes to sleep-disordered breathing and leads to sleep disorders. Polysomnography may help to clarify the association of headache and sleep disturbances.

\title{
CEREBRAL BLOOD FLOW AND MIGRAINE
}

Blood flow in the basilar and internal carotid arteries and diameters of middle meningeal, carotid, and cerebral arteries were measured using 3Tesla magnetic resonance angiography, at baseline, during infusion of nitroglycerin or placebo, and during a provoked attack, at 6 hrs after infusion, in 32 migraineurs, aged 18-55 years, in a study at Leiden University Medical Centre, the Netherlands. Migraine headache was provoked in 20/27 (74\%) migraineurs who received nitroglycerin, but in none of 5 patients who received placebo. Nitroglycerin caused a transient vasodilatation of all blood vessels. Blood vessel diameters were no different during a provoked migraine attack compared to baseline, nor between headache and non-headache sides. Blood flow in the basilar and internal carotid arteries was unchanged during nitroglycerin infusion and migraine headache. (Schoonaman GG, van der Grond J, Kortmann C, van der Geest RJ, Terwindt GM, Ferrari MD. Migraine headache is not associated with cerebral or meningeal vasodilatation - a $3 \mathrm{~T}$ magnetic resonance angiography study. B rain Aug 2008;131:2192-2200). (Respond: GG Schoonman MD, Department of Neurology (KS-Q), Leiden University Medical Centre, PO Box 9600, 2300 RC Leiden, The Netherlands. E-mail: g.g.schoonman(alumc.nl).

COMMENT. Contrary to current theory of migraine mechanisms, vasodilatation of cerebral or meningeal blood vessels is not of primary importance in the pathophysiology of the migraine headache.

\section{NEUROCUTANEOUS SYNDROMES}

\section{SYMPTOMS AND COURSE OF XERODERMA PIGMENTOSUM}

Sixteen Finnish patients with xeroderma pigmentosum (XP) were followed for up to 23 years, and their neurological symptoms and course determined in a study at Turku University Central Hospital, Finland; Erasmus University, Rotterdam, The Netherlands; University of Brighton, and University of Sussex, UK. Severe sunburn with minimal sun exposure in early infancy was the first sign of the disease in all cases, only 2 cases being diagnosed at that time. XP patients are assigned in 8 complementation groups, XP-A and XP$\mathrm{C}$ being the most common groups in Europe. Neurological symptoms occur most often in $\mathrm{XP}-\mathrm{A}$ patients. In XP-C patients, skin problems are severe, but neurological symptoms are rare.

Seven of the 16 Finnish patients were classified as XP-A. All had short stature and microcephaly. They developed normally until age 2 years, but neurological and cognitive dysfunction was apparent in childhood, before the age of 8 years. Cerebellar ataxia was recognized before age 4-16 years, followed by sensory motor neuropathy with areflexia, and sensorineural deafness. Cognitive problems were associated with an unusual tendency to weep and to be frightened. In early adulthood, 8 of 11 patients had developed choreoathetoid 